\title{
Further glycogen decrease during early recovery after eccentric exercise despite a high carbohydrate intake
}

\author{
Journal Article \\ Author(s): \\ Zehnder, Monica; Muelli, Miriam; Buchli, Reto; Kuehne, Guido; Boutellier, Urs \\ Publication date: \\ 2004-06 \\ Permanent link: \\ https://doi.org/10.3929/ethz-b-000050553 \\ Rights / license: \\ In Copyright - Non-Commercial Use Permitted \\ Originally published in: \\ European Journal of Nutrition 43(3), https://doi.org/10.1007/s00394-004-0453-7
}


Monica Zehnder

Mirjam Muelli

Reto Buchli

Guido Kuehne

Urs Boutellier
Received: 4 April 2003

Accepted: 22 September 2003

Published online: 6 January 2004
M. Zehnder · M. Muelli • R. Buchli •

U. Boutellier

Exercise Physiology

Institute for Human Movement Sciences

Swiss Federal Institute of Technology

and Institute of Physiology

University of Zurich

Zurich, Switzerland

M. Zehnder ( $\square)$

Exercise Physiology

University of Zurich-Irchel

Winterthurerstr. 190

CH-8057 Zurich, Switzerland

Tel.: + 41-1/635-5006

Fax: + 41-1/635-6863

E-Mail: zehnderm@access.unizh.ch

G. Kuehne

Paul Scherrer Institute

Villigen, Switzerland

\section{Further glycogen decrease during early recovery after eccentric exercise despite a high carbohydrate intake}

Summary Background Delayed onset muscle soreness (DOMS) is a well-known phenomenon of athletes. It has been reported from muscle biopsies that the rate of muscle glycogen resynthesis is reduced after eccentric compared to concentric exercise. Aim of the study Try to compensate by a carbohydrate (CHO)-rich diet the decelerated glycogen resynthesis after eccentric exercise, measured by magnetic resonance spectroscopy. Methods Glycogen, phosphocreatine, ATP, and Pi were measured in the human calf muscle. Twenty athletes divided into two groups (DOMS and CONTROL), reduced glycogen in M. gastrocnemius during two different running protocols. Additionally, 12 DOMS subjects performed an eccentric exercise while the CONTROL group rested. Subsequently, subjects consumed a CHO-rich diet (>10 g/kg body mass $/ 24 \mathrm{~h}$ ). Results In both groups, glycogen has been reduced by about $50 \%$. The first $2 \mathrm{~h}$ after exercise, glycogen dropped further $(-15.6 \pm 15.7 \mathrm{mmol} /$ $\mathrm{kg} \mathrm{ww}$ ) in the DOMS but rose by $+18.4 \pm 20.8 \mathrm{mmol} / \mathrm{kg} \mathrm{ww}$ in the CONTROL group $(\mathrm{P}<0.001)$. CONTROL subjects reached resting glycogen within $24 \mathrm{~h}$ $(137 \pm 47 \mathrm{mmol} / \mathrm{kg} \mathrm{ww})$, while DOMS subjects needed more than one day $(91 \pm 23 \mathrm{mmol} / \mathrm{kg} \mathrm{ww}$; $\mathrm{P}<0.001)$. $\mathrm{Pi}$ and $\mathrm{Pi} / \mathrm{PCr}$, indicators of muscle injury, rose significantly in the DOMS but not in the CONTROL group. Conclusion The diet rich in CHO's was not able to refill glycogen stores after eccentric exercise. Glycogen decreased even further during the beginning of recovery. This loss, which to our knowledge has not been measured before is probably the consequence of muscle cell damage and their reparation.

Key words magnetic resonance spectroscopy - muscle injury inorganic phosphate - delayed onset of muscle soreness

\section{Introduction}

Delayed onset muscle soreness (DOMS) is caused by exercise of unaccustomed vigor or intensity, especially by exercise involving eccentric contractions [1]. Manifestations of DOMS are muscle damage including inflammation, loss in muscle strength and range of motion, swelling release of muscle proteins in the blood, and decrement in motor control [2]. In addition, it has been reported from muscle biopsies that the rate of muscle glycogen resynthesis is reduced after eccentric compared to concentric exercise [3].

In our study, we were interested in determining if a carbohydrate (CHO)-rich diet is able to compensate for the delayed glycogen resynthesis after eccentric exercise. So far, subjects were only investigated through muscle biopsies and received less than $8.5 \mathrm{gCHO} /$ 
$\mathrm{kgBM} / 24 \mathrm{~h}$ during recovery in studies showing a delayed glycogen resynthesis after eccentric muscle contractions [4-9]. This lack of sufficient $\mathrm{CHO}$ in the diet could explain a part of the delayed glycogen resynthesis after eccentric exercise because it was shown that $10 \mathrm{~g} \mathrm{CHO} / \mathrm{kg} \mathrm{BM} / 24 \mathrm{~h}$ is necessary for a complete replenishment of glycogen stores within $24 \mathrm{~h}$ after glycogendepleting concentric exercise [10-14].

As mentioned above, glycogen resynthesis studies have mainly been conducted by the method of muscle biopsies, which have a damaging effect on muscles. Therefore, the number of measurements is limited and it is not possible to closely follow the time course of the glycogen resynthesis with this method. Furthermore, it is impossible to investigate the same muscle specimen several times because muscle biopsy sampling induces focal damage (trauma) which is not completely repaired after two weeks, and also retards the rate of glycogen resynthesis [15-17], i. e., it would interfere with the aim of our study. Finally, the major muscle damage from eccentric exercise occurs in the deepest extensor muscles and may only affect a small percentage of the fibers. It would be relatively easy to miss these sites of injury in biopsy samples from human muscles [18]. The noninvasive method of ${ }^{13} \mathrm{C}$-magnetic resonance spectroscopy (MRS), which we have applied in our study, can use an adequate diameter of the surface coil for complete measurements of fibers, which are located at some distance from the body surface and are part of the analysis. This method also allows as many measurements from the same muscle specimen as it is necessary to follow the time course of glycogen resynthesis after glycogen-reducing exercise.

Eccentric exercise followed by DOMS does not only delay glycogen resynthesis but it also affects phosphate variables. Phosphocreatine ( $\mathrm{PCr}$ ), ATP, and inorganic phosphate (Pi) are destabilized after muscle fiber injuries which occur after eccentric exercise [19]. The increase in the resting $\mathrm{Pi} / \mathrm{PCr}$ ratio in muscles, indicating a structural and cellular damage, reaches its peak 1 to 2 days after an exercise-induced injury as analyses with ${ }^{31} \mathrm{P}-\mathrm{MRS}$ have shown [20-23]. The $\mathrm{Pi} / \mathrm{PCr}$ ratio inversely reflects the oxidative capacity of the mitochondria, which is decreased after muscle damage. In addition, a decreased metabolic efficiency of ATP may occur after eccentric contractions in human muscle [19].

The aim of our study was 1) to induce muscle soreness by eccentric exercise, 2) to investigate with ${ }^{13} \mathrm{C}$-MRS whether a CHO-rich diet can reduce a delayed glycogen resynthesis during DOMS, and 3) to measure with ${ }^{31} \mathrm{P}$ MRS phosphate variables, which possibly emerge as disturbing factors for glycogen resynthesis.

\section{Methods}

\section{Subjects}

Twenty well-trained, non-smoking men volunteered to participate in the study. The risks and benefits were explained, and written informed consent was obtained from each subject. All subjects were instructed to refrain from exercise and to follow the nutritional guidelines during the course of the study starting $48 \mathrm{~h}$ before the glycogen-reducing protocol (see below) and lasting until the last MRS measurement $48 \mathrm{~h}$ after exercise. The University of Zurich Ethic's Committee of Physiology and Pharmacology approved the experimental protocol. The subjects were randomly assigned to one of the two groups (DOMS 12 subjects, CONTROL 8 subjects). The average $( \pm S D)$ age, height, and weight in the DOMS group were $34( \pm 9)$ years, $179.4( \pm 5.4) \mathrm{cm}$, and 71.0 $( \pm 6.2) \mathrm{kg}$ and in the CONTROL group $37( \pm 11)$ years, $178.9( \pm 5.0) \mathrm{cm}$, and $73.4( \pm 3.8) \mathrm{kg}$, respectively. None of the parameters showed any difference between the two groups.

\section{Experimental design}

At least one week before the experiment, each subject performed a Conconi test [24] on a treadmill (H-P-Cosmos, Nussdorf-Traustein, Germany). Depending on the training status, the subject started running with a velocity of 9 or $10 \mathrm{~km} / \mathrm{h}$. Every $200 \mathrm{~m}$, the velocity increased by $0.5 \mathrm{~km} / \mathrm{h}$ until the subject was exhausted. To supervise the cardiac frequency, each subject was equipped with a heart rate monitor (Polar Electro, Kempele, Finland). From the individual maximal velocity, we calculated the $65 \%$ velocity.

On the test day, the subjects ingested a $\mathrm{CHO}$-rich breakfast and consumed their lunch $(7 \mathrm{gCHO} / \mathrm{kg} \mathrm{BM})$, including $0.5 \mathrm{~L}$ of an isotonic drink, at least $1.5 \mathrm{~h}$ before their arrival in the laboratory at $1.30 \mathrm{p} . \mathrm{m}$. To reduce glycogen stores in the fast twitch fibers, each subject performed several bouts of sprints. Each bout corresponded to 6 sprints of $15 \mathrm{~m}$ length. As soon as a subject was more than $10 \%$ below his maximal sprint velocity, the sprints were stopped. The $65 \%$ velocity of the Conconi test was then used for a $1 \mathrm{~h}$ tread-mill run, in order to reduce the glycogen stores in the slow twitch fibers of the calf muscles. After these glycogen-reducing protocols, 12 subjects (DOMS group) performed a single-leg toe-raise exercise to induce muscle soreness. Standing in an erect position with fully extended knees and with the forefoot on a board $7 \mathrm{~cm}$ thick, the subject lifted and lowered his body by plantar and dorsi flexion of the ankle joint. Each subject completed 10 bouts of $20 \mathrm{~s}$ toeraise exercise $(1 / \mathrm{s})$ followed by $40 \mathrm{~s}$ of rest. To increase the intensity of this exercise, each subject had to 
lift $+25 \%$ of his body mass in form of dumb-bells around the hips. Instead of the eccentric exercise, the CONTROL group rested for the same amount of time.

\section{Magnetic resonance spectroscopy}

A 4.7 Tesla $30 \mathrm{~cm}$-bore spectrometer (Varian, Palo Alto, CA, USA) and a standard Varian spectral processing software were used for the in vivo MRS measurements. Two concentric, radiofrequency (rf) surface coils in $6 \mathrm{~cm}$ of diameter for ${ }^{31} \mathrm{P}$ and of $10 \mathrm{~cm}$ in diameter for ${ }^{13} \mathrm{C}$ were used to transmit and receive the signals. Both coils were placed under the center of the right calf muscle (M.gastrocnemius and M. soleus) of each subject and were frequency-tuned to $80.98 \mathrm{MHz}$ for the ${ }^{31} \mathrm{P}-$ and to $50.31 \mathrm{MHz}$ for the ${ }^{13} \mathrm{C}$-MRS measurements. To assure the same coil position in the subjects for each measurement, a fit for the right calf and heel was constructed. Additionally, waterproof marks on the skin provided an exact repositioning until the end of the experiment. A sticky tape tagged each subject's leg to the fit to inhibit any movement.

Small external reference samples of phenylphosphoric acid for ${ }^{31} \mathrm{P}$ and of formic acid for ${ }^{13} \mathrm{C}$ were placed at the center of the two concentrical coils. First, they had to control the stability of the RF signal and of its amplification during the whole experiment. Second, they optimized the RF pulse power in order to achieve a precise $180^{\circ}$ flip angle in the center of the RF coil. This $180^{\circ}$ pulse guaranteed that the main signal was collected from the deeper part of M. gastrocnemius and not the one adjacent to the coil. Before each measurement, the homogeneity of the static magnetic field was adjusted with an automatic shimming procedure $\left(\mathrm{x}, \mathrm{y}, \mathrm{z}, \mathrm{x}^{2}, \mathrm{y}^{2}, \mathrm{z}^{2}\right.$, and $\mathrm{x}^{2}$ $\left.\mathrm{y}^{2}\right)$ using proton signals from water.

\section{${ }^{13} \mathrm{C}$-spectra: aquisition and quantification}

Glycogen concentration was measured in the calf muscle before (Pre exercise) and 0 (Post exercise for the DOMS, Post resting for the CONTROL group), 2, 15, 24, and $48 \mathrm{~h}$ after exercise by ${ }^{13} \mathrm{C}$-MRS (Fig. 1 ). The interpulse delay (repetition time $=\operatorname{Tr}$ ) was $0.15 \mathrm{~s}$ and the partial saturation of the glycogen signal was corrected by determining its relaxation time (T1) in the calf muscle at 4.7 Tesla. For a better signal-to-noise ratio, 6000 free induction decays were sampled before Fourier transformation. The spectra were collected using a simple pulseacquire sequence.

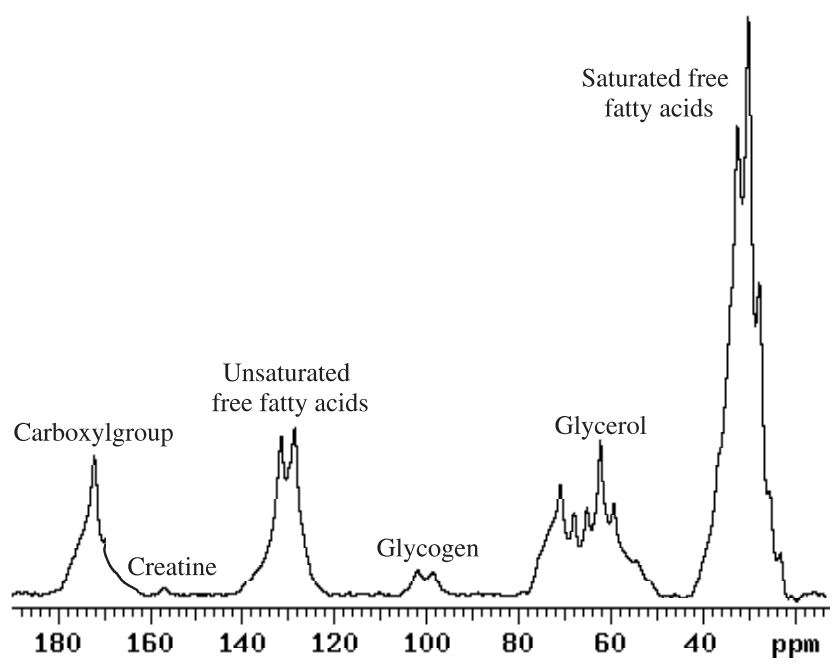

Fig. 1 Natural abundance, undecoupled ${ }^{13} \mathrm{C}-\mathrm{MR}$ spectrum of the M. gastrocnemius and M. soleus of a subject before exercise. Resonances 104 to $98 \mathrm{ppm}$ are from $\mathrm{C} 1$ of muscle glycogen

\section{P-spectra: acquisition and quantification}

PCr, ATP, and Pi concentrations were determined after the glycogen measurements by ${ }^{31} \mathrm{P}$-MRS (Fig. 2). The interpulse delay $\operatorname{Tr}$ was $4 \mathrm{~s}$. The T1 values of the muscle metabolites were obtained in four subjects to correct the partial saturation effect. In order to increase the signal-

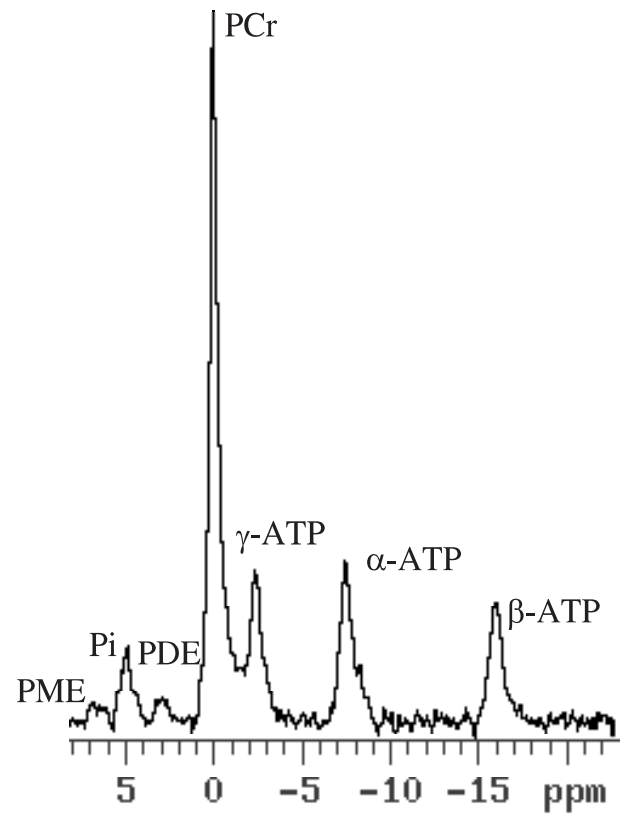

Fig. 2 Typical resting ${ }^{31} \mathrm{P}-\mathrm{MR}$ spectrum of the M. gastrocnemius and M. soleus of a subject. Resonances are from phosphomonoesters (PME, $6.5 \mathrm{ppm})$, inorganic phosphate ( $\mathrm{Pi}, 5 \mathrm{ppm})$, phosphodiesters ( $\mathrm{PDE}, 3 \mathrm{ppm})$, phosphocreatine $(\mathrm{PCr}, 0$ $\mathrm{ppm})$ and the three different adenosine triphosphates $(\gamma-, \alpha-, \beta-$ ATP,-2.5 to -16 $\mathrm{ppm})$ 
to-noise ratio, 100 free induction decays were sampled, phased, and baseline corrected.

\section{Processing of the ${ }^{31} \mathrm{P}$ - and ${ }^{13} \mathrm{C}$-spectra and fitting of the peaks}

At the end of each measurement, the spectra were phased, baseline corrected and finally fitted in order to determine the peak areas of the resonance lines of the investigated metabolites. In order to avoid severe systematic errors due to baseline distortion and peak overlapping, integration is not valid. Therefore we fitted our data in the time as well as in the frequency domain. The time domain fitting was performed with an iterative least-squares method. Exponentially decreasing model signals were fitted to the experimental signals. These model signals were converted into Lorentzian lines by Fourier transformation. Iteration was started with a list of model signals, one signal for each in vivo resonance. The first two milliseconds of the experimental signal were omitted for fitting in order to avoid the strong but fast dephasing signal of the almost immobile membrane molecules.

\section{Quantification of the glycogen and phosphate peaks}

${ }^{13} \mathrm{C}$-quantification was achieved with a calibration phantom used as a concentration standard. A cylindrical $2 \mathrm{~L}$ bottle was filled with a solution of $100 \mathrm{mmol} / \mathrm{L}$ of oyster glycogen buffered to a $\mathrm{pH}$ of 7.2 and supplemented with sodium acid to impair bacterial influence. The natural abundance of ${ }^{13} \mathrm{C}$ was identical in the oyster glycogen and the in vivo muscle glycogen. As the signal intensity of partially relaxed glycogen depends on the temperature of the solution, the glycogen phantom was warmed up to $37^{\circ} \mathrm{C}$. The in vivo (muscle glycogen) and in vitro (phantom oyster glycogen) measurements were identical with respect to all measurement parameters, to the area investigated in the tissue respectively phantom, and to the load of the RF-coil. The coil load for the calibration measurement was adjusted to match the one of the muscle examination in the following way: after the in vivo measurement, the matching capacitance of the RF-coil was left unchanged. In contrast, the coil load of the calibration measurement was successively increased with a small saline bottle, which was gradually brought closer to the phantom-loaded RF-coil until identical matching was achieved. The electrical conductivity of the phantom solution was improved by adding $\mathrm{NaCl}(\sigma=0.65 \mathrm{~S} / \mathrm{m})$ and was slightly kept below the one of human tissue $(\sigma=0.69$ $\mathrm{S} / \mathrm{m}$ ) in order to allow the described fine adjustment of the coil load with the small saline bottle.

In a pilot study, the accuracy and reproducibility of the glycogen quantification with and without proton de- coupling was examined. The calibration strategy using an external phantom was significantly more accurate if proton decoupling was not applied. The reason therefor is probably the heat deposition pattern, which develops during decoupling and differs greatly between a phantom and human tissue. As a high field 4.7 Tesla spectrometer has been used, an excellent $\mathrm{S} / \mathrm{N}$ ratio $(>10)$ was obtained for glycogen and a decrease in peak height by a factor of two could be afforded. Thus, peak fitting was not a problem. It was rather more accurate as a lifelike ${ }^{13} \mathrm{C}$-spectrum shows two peaks of glycogen instead of one after decoupling.

The quantification of the ${ }^{31} \mathrm{P}$-spectra, using a replacement phantom, was done by the same procedure as described above. Immediately after the in vivo session, an identical in vitro measurement was performed with a $2 \mathrm{~L}$ calibration phantom containing a solution of $50 \mathrm{mmol} / \mathrm{L}$ of $\mathrm{KH}_{2} \mathrm{PO}_{4}$.

In order to compare quantified glycogen, PCr, ATP, and $\mathrm{Pi}$ with results from other human studies, muscle metabolite concentrations were converted from $\mathrm{mmol} / \mathrm{L}$ to $\mathrm{mmol} / \mathrm{kg}$ wet weight ( $\mathrm{ww}$ ), using the constant value of $1.04 \mathrm{~kg} / \mathrm{L}$ for the specific gravity of muscle tissue [25].

\section{Blood sampling and analyses}

Blood samples for the examination of glucose, insulin, free fatty acid (FFA), $\beta$-hydroxybutyrate $(\beta-\mathrm{Hb})$, creatine kinase $(\mathrm{CK})$, myoglobin $(\mathrm{Mb})$, and lactate were drawn from an antecubital vein of the left arm. The first blood sample was drawn before exercise (after resting $30 \mathrm{~min}$ in a supine position), the following samples 0,2 , 15,24 , and $48 \mathrm{~h}$ after exercise. The blood for the analyses of insulin, FFA, CK, and $\mathrm{Mb}$ was filled in a $7.5 \mathrm{ml}$ EDTA tube containing $\mathrm{NH}_{4}$-heparin (Sarstedt, Nümbrecht, Germany). The blood for the analyses of glucose, $\beta-\mathrm{Hb}$, and lactate was collected in a $2.7 \mathrm{ml} \mathrm{NaF}$ tube. Following centrifugation ( 4800 revolutions $/ \mathrm{min}$ at $4{ }^{\circ} \mathrm{C}$ for $15 \mathrm{~min}$ ) the plasma was separated from the erythrocytes and stored until analysis at $-80^{\circ} \mathrm{C}$. Lactate and glucose were analyzed with an enzymatic calorimetrical method, $\beta$ $\mathrm{Hb}, \mathrm{CK}$, and FFA by a photometric-enzymatic method. Lacate was measured with a test kit of Bergmeyer (New York, USA), glucose, $\beta$ - Hb, and CK with the Cobas Mira (Roche, Basel, Switzerland), and FFA by a kit of WAKO (Neuss, Germany). Insulin and Mb were determined by radioimmunoassay. Insulin with a test kit of INSI-PR Cis bio international (Sur-Yvette Cedex, France) and Mb by a test kit of immuno diagnostic center (Dallas, USA).

\section{Diet analyses}

Starting two days before the experiment, subjects were told to eat foods selected from a list of $\mathrm{CHO}$-rich meals 
and to additionally ingest $1 \mathrm{~L}$ of an isotonic drink every evening, made of maltodextrine powder, to ensure full muscle glycogen stores. If the subjects were not able to eat all of the suggested food, they had to record it. The subjects were not allowed to ingest any drink containing caffeine from $24 \mathrm{~h}$ before the start until the end of the experiment. At least $1.5 \mathrm{~h}$ before their arrival in the laboratory on the experimental day, the subjects consumed a $\mathrm{CHO}$-rich lunch, including again $0.5 \mathrm{~L}$ of the isotonic drink. From the moment the subjects were in the laboratory and started the experiment, they were allowed to eat and drink only the food prepared by us to ensure that every subject ingested at least $10 \mathrm{~g} \mathrm{CHO} / \mathrm{kg} \mathrm{BM} / 24 \mathrm{~h}$ during recovery. To optimize glycogen resynthesis after the reducing exercise, the meals were composed of dried fruits, gingerbread, rice pudding, pasta, rice, etc., and an isotonic drink. The snack given immediately after exercise (Table 1) and the dinner on the testing day were consumed in the laboratory. On the next day, the subjects consumed the delivered breakfast at home, $1.5 \mathrm{~h}$ before the $15 \mathrm{~h}$ post exercise MRS measurements. From $15 \mathrm{un}$ til $24 \mathrm{~h}$ after exercise, the subjects stayed in the laboratory again and consumed the morning snack, lunch, and afternoon snack under our supervision (Table 1). The subjects took the dinner, which they consumed after the $24 \mathrm{~h}$ MRS measurements, and all the other prepared foods for the second day with them. If anything was left over, they brought it back to the laboratory before the last MRS measurements ( $48 \mathrm{~h}$ after exercise). The food records were analyzed using a standard nutrition analysis software package (EBIS 2.0; E + D Partner, Stuttgart, Germany).

\section{Perceived muscle soreness}

Muscle soreness in the calf muscle was rated according to a modified Borg scale ranging from 0 (nothing at all sore) to 10 (maximally sore) and was determined by ask- ing the subject while walking slowly. Always the same investigator performed the soreness recording before each withdrawal of blood.

\section{Statistical analyses}

The results are presented as mean value \pm standard deviation (SD). Differences over time between the two groups (DOMS and CONTROL, respectively) were analyzed by multiple analysis of variance (MANOVA) and, if significant, indicated with an asterisk $\left({ }^{*}\right)$. Differences within each group were tested by one-way analysis of variance (ANOVA-factorial) followed by Fisher's testing for significance. Within a group, a plus $(+)$ shows significant differences from the base value before exercise. Linear regression analysis was performed with standard procedures.

\section{Results}

\section{Glycogen-reducing exercises}

The DOMS group sprinted for $6.1 \pm 3.3$ min with an average heart rate of $155.4 \pm 11.0$ beats/min and the CONTROL group for $7.9 \pm 5.2 \mathrm{~min}$ with a heart rate of $158.5 \pm 11.4$ beats $/ \mathrm{min}$. Afterwards, all subjects finished the $1 \mathrm{~h}$ running protocol at $65 \%$ maximal performance (DOMS: $12.0 \pm 1.1 \mathrm{~km} / \mathrm{h}$; CONTROL: $11.1 \pm 1.6 \mathrm{~km} / \mathrm{h}$ ), determined by the Conconi test previously. The average heart rate amounted to $151.7 \pm 14.0$ beats $/ \mathrm{min}$ in the DOMS and $154.4 \pm 11.5$ beats $/ \mathrm{min}$ in the CONTROL group. None of the comparisons between the two groups showed a significant difference.
Table 1 Food ingested by the subjects after the exercise until the end of the experiment $48 \mathrm{~h}$ later

\begin{tabular}{|c|c|c|}
\hline When & Food & $\mathrm{g}$ CHO/Portion \\
\hline Snack after exercise & $0.5 \mathrm{~L}$ isotonic drink, $150 \mathrm{~g}$ apple puree & 112 \\
\hline Dinner after exercise & $\begin{array}{l}75 \mathrm{~g} \text { apricot pie, } 280 \mathrm{~g} \text { rice, } 160 \mathrm{~g} \text { mixed vegetables, } \\
2 \mathrm{dl} \mathrm{mushroom} \mathrm{sauce,} \mathrm{water} \mathrm{ad} \mathrm{libitum}\end{array}$ & 161 \\
\hline $\begin{array}{l}\text { Day } 1 \text { and } 2 \text { after exercise } \\
\text { Breakfast }\end{array}$ & $\begin{array}{l}132 \mathrm{~g} \text { toast ( } 6 \text { slices), } 40 \mathrm{~g} \text { honey, } \\
150 \mathrm{~g} \text { banana chips yogurt, } 3 \mathrm{dl} \text { orange juice }\end{array}$ & 171 \\
\hline Morning snack & $\begin{array}{l}100 \mathrm{~g} \text { dried fruit, } 75 \mathrm{~g} \text { gingerbread stuffed with } \\
\text { almond paste, } 3 \mathrm{dl} \text { apple juice }\end{array}$ & 135 \\
\hline Lunch & $\begin{array}{l}5 \mathrm{dl} \text { herbal ice tea, } 132 \mathrm{~g} \text { toast ( } 6 \text { slices), } \\
75 \mathrm{~g} \text { pear bread, } 200 \mathrm{~g} \text { rice pudding }\end{array}$ & 199 \\
\hline Afternoon snack & $\begin{array}{l}100 \mathrm{~g} \text { dried fruit, } 42 \mathrm{~g} \text { crunchy chocolate bar, } \\
3 \mathrm{dl} \text { orange juice }\end{array}$ & 110 \\
\hline Dinner & 180 g pasta, 75 q pear bread, $0.5 \mathrm{~L}$ isotonic drink & 246 \\
\hline
\end{tabular}




\section{Nutrition}

Table 2 presents the average results of the daily-ingested macronutrients and energy in both groups, which were similar. The intake of more than $10 \mathrm{~g} \mathrm{CHO} / \mathrm{kg} \mathrm{BM} / 24 \mathrm{~h}$ was achieved during recovery as intended.

\section{Glycogen metabolism}

Fig. 3 shows the different ${ }^{13} \mathrm{C}-\mathrm{MRS}$ measurements of muscle glycogen. Sprinting and running in both groups, and the additional eccentric exercise performed by the DOMS group, significantly reduced the glycogen concentrations identically by about $50 \%(\mathrm{P}<0.001)$. The concentration dropped further by $7.8 \pm 7.9 \mathrm{mmol} /$ $\mathrm{kg} \mathrm{ww} / \mathrm{h}$ in the first $2 \mathrm{~h}$ of recovery in the DOMS group and increased by $9.2 \pm 10.4 \mathrm{mmol} / \mathrm{kg} \mathrm{ww} / \mathrm{h}$ during the same time period in the CONTROL group $(\mathrm{P}<0.001)$. In the following hours, there was a trend for lower glycogen

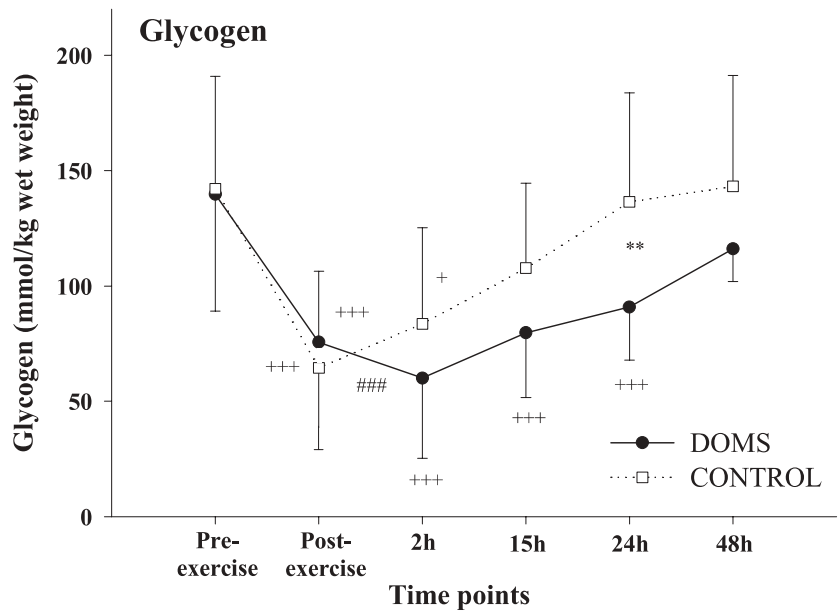

Fig. 3 Muscle glycogen concentrations of the DOMS $(N=12)$ and CONTROL $(\mathrm{N}=8)$ group. Significant differences between the two groups are indicated with an asterisk $(*)$. Within a group, a plus $(+)$ shows significant differences between Pre and any Post exercise concentration. In addition, a pound sign (\#) shows significant differences between the glycogen resynthesis rates of the two groups. $+: \mathrm{P}<0.05$; **: $P<0.01 ;+++, \# \# \#: P<0.001$. Values are means $\pm S D$ concentrations in the DOMS compared to the CONTROL group (15 h: $\mathrm{P}=0.07 ; 24 \mathrm{~h}: \mathrm{P}<0.01 ; 48 \mathrm{~h}: \mathrm{P}=0.08$ ). The glycogen concentration of the DOMS group was still significantly $(\mathrm{P}<0.001)$ below the resting concentration $24 \mathrm{~h}$ after exercise. Only after $48 \mathrm{~h}$ was the glycogen concentration no different from the resting level, whereas the CONTROL group achieved this already after $15 \mathrm{~h}$.

\section{Phosphate metabolism}

Whereas the PCr, ATP, and Pi concentrations (Fig. 4) of the DOMS group differed significantly from the base value, this was not the case in the CONTROL group (one exception: $\mathrm{PCr}$ at $24 \mathrm{~h} ; \mathrm{P}<0.05)$. In the DOMS group, the $\mathrm{PCr}$ concentration was significantly higher $(\mathrm{P}<0.01)$ compared to the resting level up to $15 \mathrm{~h}$ after exercise, which resulted in a significant difference between the two groups $(\mathrm{P}<0.01)$. The ATP concentration declined immediately after exercise and remained significantly below the resting concentration until the end of the study $(\mathrm{P}<0.001)$. Therefore, the DOMS group significantly differed from the CONTROL group during most of the recovery period $(\mathrm{P}<0.001)$. The Pi drop during exercise in the DOMS group and the following rise over $48 \mathrm{~h}$ were significant $(\mathrm{P}<0.01)$ and showed a significant difference to the CONTROL group during the first $24 \mathrm{~h}$ $(\mathrm{P}<0.01)$.

\section{Blood parameters}

None of the blood concentrations of $\mathrm{CK}, \mathrm{Mb}$, lactate, glucose, insulin, FFA, and $\beta$-Hb showed a difference between the two groups over time (Fig. 5). Subsequently, only $\mathrm{CK}$ and $\mathrm{Mb}$, which are consistently mentioned in connection with DOMS, will be described in more detail. CK rose until it was significantly above the base value after $15 \mathrm{~h}(\mathrm{P}<0.01)$ in both groups. It remained elevated $(\mathrm{P}<0.01)$ until the end of the study in the DOMS group and up to $24 \mathrm{~h}$ in the CONTROL group $(\mathrm{P}<0.01)$. Contrary to $\mathrm{CK}, \mathrm{Mb}$ was already significantly increased after exercise in both groups, remained increased up to
Table 2 Average $24 \mathrm{~h}$-intake of macronutrients and energy during $48 \mathrm{~h}$ before and after glycogen-reducing exercise with additional eccentric contractions (DOMS) or without eccentric exercise (CONTROL)

\begin{tabular}{llrrrr}
\hline Nutrients/Energy & Group & \multicolumn{1}{l}{$-48 \mathrm{~h}$} & \multicolumn{1}{l}{$-24 \mathrm{~h}$} & \multicolumn{1}{l}{$+24 \mathrm{~h}$} & $+48 \mathrm{~h}$ \\
\hline Carbohydrates (g/kg BM/24 h) & DOMS & $9.1 \pm 2.4$ & $10.0 \pm 2.7$ & $12.4 \pm 0.8$ & $11.8 \pm 1$ \\
& CONTROL & $7.4 \pm 3.3$ & $8.2 \pm 2.2$ & $11.9 \pm 0.7$ & $11.0 \pm 1$ \\
Fat (g/kg BM/24 h) & DOMS & $1.1 \pm 0.5$ & $0.9 \pm 0.3$ & $1.0 \pm 0.1$ & $0.9 \pm 0.2$ \\
& CONTROL & $0.9 \pm 0.5$ & $0.8 \pm 0.2$ & $1.1 \pm 0.2$ & $0.8 \pm 0.1$ \\
Protein (g/kg BM/24 h) & DOMS & $1.4 \pm 0.6$ & $1.5 \pm 0.5$ & $1.2 \pm 0.2$ & $1.1 \pm 0.2$ \\
& CONTROL & $1.1 \pm 0.6$ & $1.2 \pm 0.2$ & $1.2 \pm 0.2$ & $1.1 \pm 0.2$ \\
Energy (MJ/24 h) & DOMS & $15.9 \pm 4.3$ & $16.7 \pm 3.8$ & $19.4 \pm 1.43$ & $18.5 \pm 1.4$ \\
& CONTROL & $13.9 \pm 6.1$ & $14.4 \pm 2.8$ & $20.1 \pm 1.2$ & $17.7 \pm 1.3$ \\
\hline
\end{tabular}

The results are presented as mean value \pm standard deviation. $N=12$ (DOMS) and 8 (CONTROL), respectively 


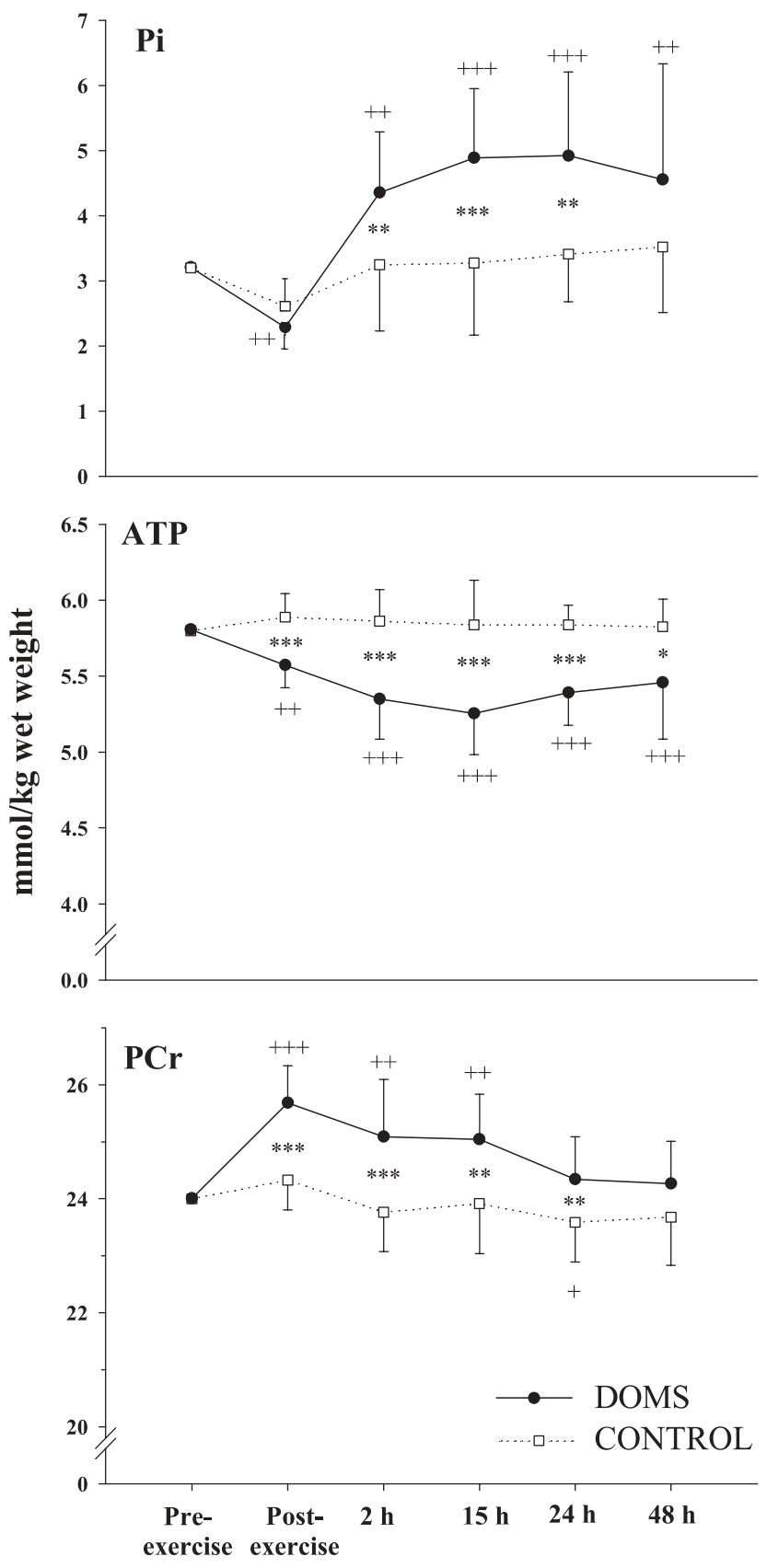

Time points

Fig. 4 Pi, ATP, and PCr concentrations of the DOMS ( $N=12)$ and CONTROL $(N=8)$ group. Significant differences between the two groups are indicated with an asterisk $\left.{ }^{*}\right)$. Within a group, a plus $(+)$ shows significant differences between Pre and any Post exercise concentration. ${ }^{*},+: \mathrm{P}<0.05 ;{ }^{* *},++$ : $\mathrm{P}<0.01 ;{ }^{* * *},+++$ : $P<0.001$. Values are means $\pm S D$

$2 \mathrm{~h}(\mathrm{P}<0.001)$, and fell back to normal values thereafter. $\mathrm{Mb}$ started to increase again after $24 \mathrm{~h}$ in the DOMS group. However, this slight increase did not reach a significant level. Additionally, a few correlations were observed between $\mathrm{Mb}$ and perceived soreness (after $24 \mathrm{~h}$ : $\mathrm{r}^{2}=0.27 ; \mathrm{P}<0.08$ ) as well as $\mathrm{Mb} / \mathrm{CK}$ and $\mathrm{Pi} / \mathrm{PCr}$ ratio (after $\left.15 \mathrm{~h}: \mathrm{r}^{2}=0.4 ; \mathrm{P}<0.05 / \mathrm{r}^{2}=0.5 ; \mathrm{P}<0.01\right)$ in the DOMS but not in the CONTROL group.

\section{Muscle soreness}

Both groups showed a significant increase of the perceived soreness immediately after exercises $(P<0.001$; Fig. 6). Testing of the differences between the two groups revealed a significantly higher perceived soreness rating in the DOMS group after $48 \mathrm{~h}(\mathrm{P}<0.05)$, which started with a trend after $24 \mathrm{~h}(\mathrm{P}=0.07)$. The toe-raise exercise additionally significantly increased the $\mathrm{Pi} / \mathrm{PCr}$ ratio after $15 \mathrm{~h}(\mathrm{P}<0.001$; Fig. 6$)$ in the DOMS group. This ratio remained higher than the resting ratio until the end of the study, whereas in the CONTROL group it always showed resting values. Comparing the two groups, the DOMS group had a significantly higher $\mathrm{Pi} / \mathrm{PCr}$ ratio after 15 and $24 \mathrm{~h}(\mathrm{P}<0.01)$. After 2 and $48 \mathrm{~h}$, but not after 15 and $24 \mathrm{~h}$, there was a significant correlation between perceived soreness and $\mathrm{Pi} / \mathrm{PCr}$ ratio in the DOMS (Fig. 7) but not in the CONTROL $\left(\mathrm{r}^{2}=0.03 ; \mathrm{P}=0.67\right.$ and $\mathrm{r}^{2}=0.03 ; \mathrm{P}=0.68$, respectively) group.

\section{Discussion}

Muscle glycogen concentration was equally lowered after running and sprinting irrespective of whether subjects rested or performed an additional eccentric exercise. Eccentric exercise of the DOMS group successfully induced muscle soreness. The CHO-rich diet immediately consumed after exercise not only failed to prevent delayed glycogen resynthesis. Glycogen even further decreased during the first $2 \mathrm{~h}$ of recovery in the DOMS subjects $(-15.6 \pm 15.7 \mathrm{mmol} / \mathrm{kg} \mathrm{ww})$ in contrast to the CONTROL group, where glycogen started to refill $(+18.4 \pm 20.8 \mathrm{mmol} / \mathrm{kg} \mathrm{ww})$. This decrease in glycogen concentration after eccentric exercise is reported here for the first time and has not been seen in previous studies, which measured glycogen after 4 to $6 \mathrm{~h}$ of exercise [e.g. 6, 9, 12]. The further glycogen loss during early recovery is especially disadvantageous because the first $2 \mathrm{~h}$ of exercise recovery are normally characterized by a rapid, insulin independent, glycogen resynthesis phase [26]. The averaged glycogen resynthesis rate of $9.2 \pm 10.4 \mathrm{mmol} / \mathrm{kg} \mathrm{ww} / \mathrm{h}$ found in the CONTROL group corresponded to what is described in other studies [8, 26].

Several factors may account alone or in combination for the further decrease in glycogen concentration found during the first $2 \mathrm{~h}$ after vigorous eccentric exercise followed by muscle soreness. A significant rise of $\mathrm{Pi}$ $(\mathrm{P}<0.001)$ was measured during the first $2 \mathrm{~h}$ (Fig. 4$)$. This elevated Pi concentration persisted during at least 

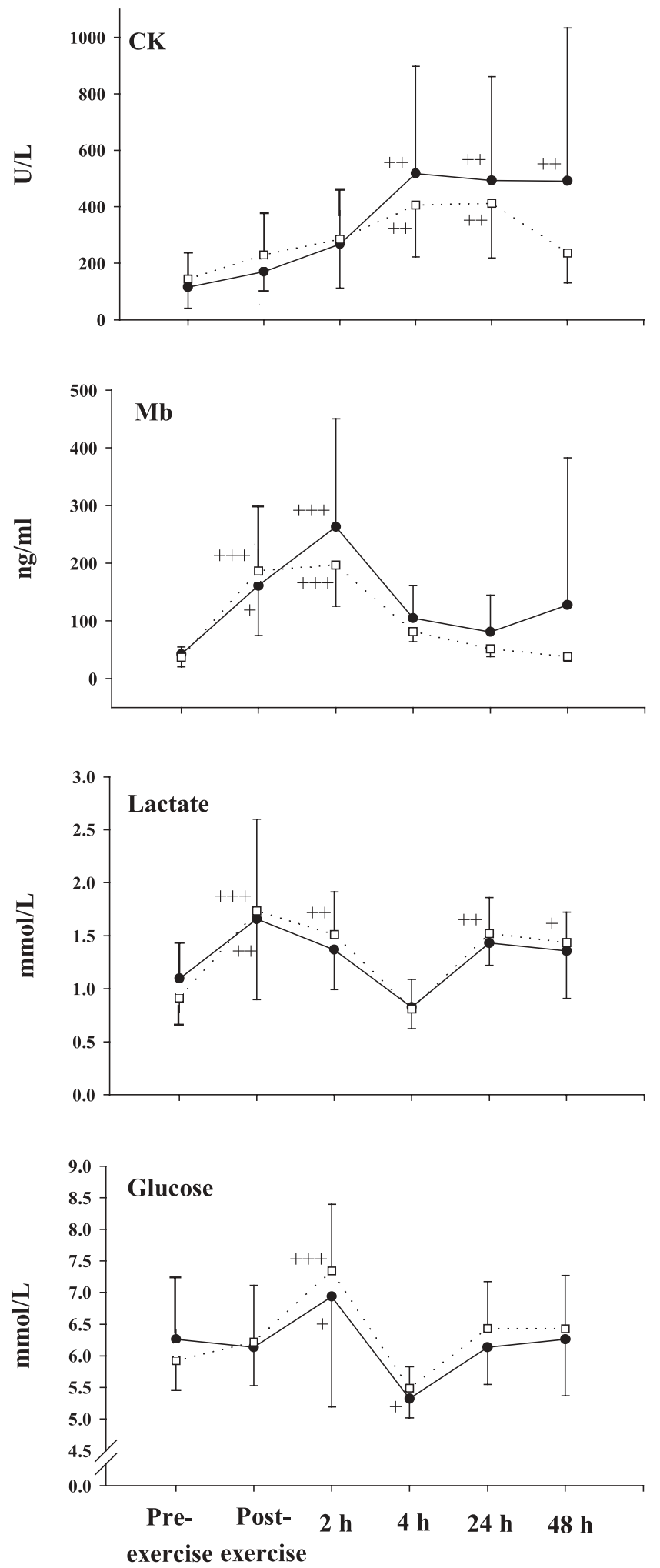

Time points
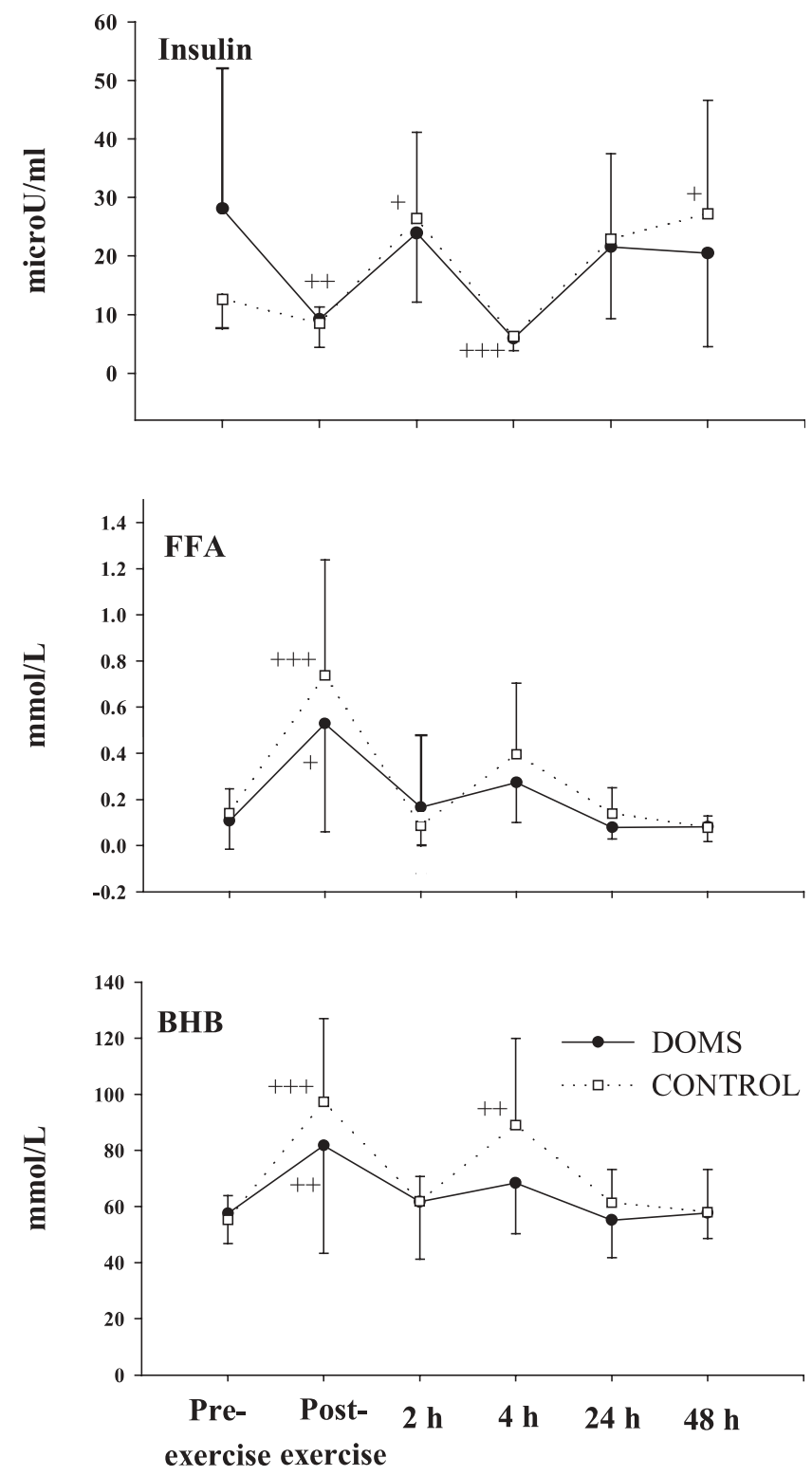

Time points

Fig. 5 Concentrations of creatine kinase (CK), myoglobin (Mb), lactate, glucose, insulin, free fatty acids (FFA), and beta hydroxy butyrate $(\beta-\mathrm{Hb})$ of the DOMS $(\mathrm{N}=12)$ and $\mathrm{CONTROL}(\mathrm{N}=8)$ group. No significant differences between the two groups were found. Within a group, a plus $(+)$ shows differences between Pre and any Post exercise concentration. + : $\mathrm{P}<0.05 ;++$ : $\mathrm{P}<0.01 ;+++$ : $\mathrm{P}<0.001$. Values are mean \pm SD

$24 \mathrm{~h}$ and was also responsible for an increased $\mathrm{Pi} / \mathrm{PCr}$ ratio in the DOMS group during recovery (Fig.6). Increased $\mathrm{Pi}$ and $\mathrm{Pi} / \mathrm{PCr}$ are indicators of muscle cell damage $[20,21]$. McCully etal. [21] suggested that the steepness of the slope of the $\mathrm{Pi} / \mathrm{PCr}$ ratio could indicate the severity of the exercise-induced muscle injury. In addition, a shallower $\mathrm{Pi} / \mathrm{PCr}$ ratio curve points to a preser- 

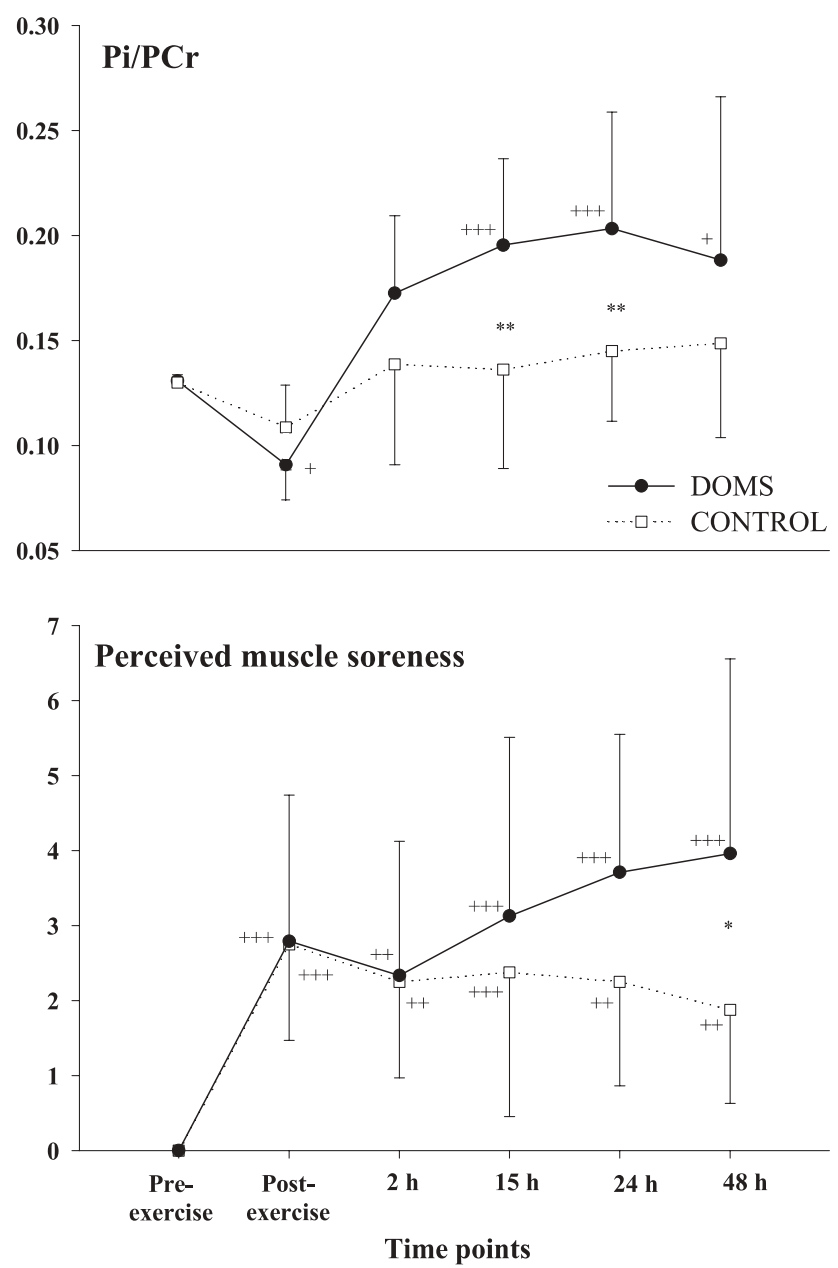

Fig. $6 \mathrm{Pi} / \mathrm{PCr}$ ratio and perceived muscle soreness of the DOMS $(\mathrm{N}=12)$ and CONTROL ( $(\mathrm{N}=8)$ group. Significant differences between the two groups are indicated with an asterisk $(*)$. Within a group, a plus $(+)$ shows significant differences between Pre and any Post exercise value. ${ }^{*},+: \mathrm{P}<0.05 ;{ }^{*}{ }^{*}++: \mathrm{P}<0.01 ;+++$ $P<0.001$. Values are means $\pm S D$

vation of $\mathrm{PCr}$ as it also happened in our CONTROL group. In the present study, the slope of the $\mathrm{Pi} / \mathrm{PCr}$ ratio was highest during the first $2 \mathrm{~h}$ after eccentric exercise (DOMS group: $+0.09 \pm 0.05$; CONTROL group: $+0.03 \pm 0.06$; $\mathrm{P}<0.05$; Fig. 6 ). This result of the DOMS group is in close relation with the result of McCully et al. [20], where $24 \mathrm{~h}$ after repeated lengthening contraction exercise resulting in muscle injury, the subjects showed a maximum $\mathrm{Pi} / \mathrm{PCr}$ ratio increase $(+0.1)$. Also, Lund et al. [27] described the elevated $\mathrm{Pi} / \mathrm{PCr}$ as a reliable indicator for muscle injury after eccentric exercise. Therefore, we assume that in the present study the eccentric exercise, followed by DOMS, caused muscle fiber injury observable already early during recovery. This assumption is realistic because O'Reilly and colleagues [28] showed numerous ultra-structural abnormalities in muscle cells immediately after eccentric exercise as, e.g., focal myofibrillar lysis or damage to the sarcoplasmic reticulum.

During eccentric toe-raise exercise with fully extended knees, M. gastrocnemius is predominately strained. M. gastrocnemius contains mainly fast-twitch fibers. These fibers are characterized by an increased intramuscular Pi concentration after muscle injury [29]. Pi is one of the substrates for phosphorylation and activated by glycogenolysis, especially in fast-twitch muscles [29]. Moreover, phosphorylase a is also activated by elevations in intracellular $\mathrm{Ca}^{2+}$ levels, which occur after fiber injury and result in glycogenolysis [30].

Furthermore, Hultman and Greenhaff [31] described that eccentric exercise causes metabolic perturbations in muscle fibers. Type II fibers were unable to maintain a high rate of ATP resynthesis for energy provision, as it is necessary, e.g., for glycogen resynthesis. This happened most likely also in the present study because the DOMS group had a significantly lower ATP concentration $(\mathrm{P}<0.001)$ than the CONTROL group after exercise (Fig. 4). The diminished ATP concentration and its negative consequences for glycogen resynthesis in the DOMS group may be also explained by the evoked microruptures. The result is an uptake of $\mathrm{Ca}^{2+}$ into the sarcoplasma, followed by a disturbance of the oxidative phosphorylation, which reduces ATP resynthesis [32].

Ryschon etal. [19] estimated the efficiency of ATP utilization for concentric, eccentric, and isometric muscle action. A higher metabolic efficiency during an eccentric compared to a concentric action followed a lower ATP resynthesis rate after eccentric action. An explanation for this is the recruitment of more efficient fibers during eccentric compared to concentric exercise [19]. Therefore, we could assume that the ingested $\mathrm{CHO}$ in the DOMS group was rather used to provide energy for, e. g., the regeneration of the hydrolized ATP than being used to restore muscle glycogen during the initial $2 \mathrm{~h}$ of recovery.

The influence of eccentric exercise on phosphate metabolism and glycogen resynthesis was not only seen after $2 \mathrm{~h}$. The trend for different glycogen concentrations between the two groups after $15 \mathrm{~h}(\mathrm{P}<0.07)$ and the significant difference after $24 \mathrm{~h}(\mathrm{P}<0.01$, Fig. 3$)$ was paralleled by a significant difference in the $\mathrm{Pi} / \mathrm{PCr}$ ratio $(\mathrm{P}<0.01$, Fig. 6). The higher Pi/PCr ratios in the DOMS group can still reflect the disrupted muscle fibers. Damaged muscle fibers lead in turn to a defect in oxidative metabolism, i. e., in our study to a perturbation of the phosphate equilibrium, which enables an influx of plasma Pi [33]. Additionally, it can also be a sign of an increased oxidative capacity of mitochondria [21], which evokes increased energy demand. This increased energy demand might be a result of the healing process of the injured fibers. Therefore, also after $2 \mathrm{~h}$ glucose could provide energy for the ATP resynthesis used for 
the healing process rather than for the glycogen resynthesis. This is in accordance with a reduced glycogen resynthesis between post exercise and $15 \mathrm{~h}$ of only $4 \pm 28 \mathrm{mmol} / \mathrm{kg}$ ww in the DOMS compared to $43 \pm$ $26 \mathrm{mmol} / \mathrm{kg}$ ww in the CONTROL group (Fig. 3).

Additionally, different studies [4,34-36] investigated the influence of glucose transport proteins (GLUT 4) in connection with eccentric exercise and impaired glycogen resynthesis. They found, on the one hand, a reduced amount of GLUT 4 in damaged muscle cells [4], on the other hand, a diminished function, caused by a relatively short-term insulin resistance after eccentric exercise $[35,36]$. In a newer study, Asp et al. [34] measured a delay of muscle glycogen resynthesis after a muscle damage inducing marathon run although GLUT 4 concentration was unaltered. Therefore, they concluded that factors other than GLUT 4 concentration must be involved in the slow glycogen resynthesis. Compared to our study, the subjects consumed less $\mathrm{CHO}$ (only $7 \mathrm{gCHO} / \mathrm{kgBM} / 24 \mathrm{~h}$ ) during the recovery from the marathon and it is not clear whether the subjects received $\mathrm{CHO}$ immediately after exercise. Therefore, one could argue if "immediately administered" or more $\mathrm{CHO}$ would have reduced or prevented the delayed glycogen resynthesis. However, from the previous insights of our study this option has to be abandoned.

From Kapur et al. [37] and Schmidt and Walter [38] a further potential explanation arises for the diminished glycogen resynthesis of the DOMS compared to the CONTROL group. It concerns the cytokine-inducible enzyme, one of the three different nitric oxide synthase isozymes, which is most evident in fast-type extensor muscles [39]. On the one hand, the enzyme is enhanced during inflammation and, on the other hand, its activity causes impaired insulin-stimulated glucose uptake. The impaired insulin activity would reduce muscle glucose uptake and therefore glycogen resynthesis.

Besides $\mathrm{Pi}, \mathrm{Pi} / \mathrm{PCr}$ ratio, and probably the cytokineinducible enzyme, muscle soreness is another reliable indicator for muscle damage. The $\mathrm{Pi} / \mathrm{PCr}$ ratio of the DOMS group correlated significantly with the perceived muscle soreness $2 \mathrm{~h}$ post exercise $(\mathrm{P}<0.001$; Fig. $7 \mathrm{~A})$. Soreness follows muscle injury, which is mostly caused by eccentric exercise [e.g., 4]. McCully et al. [20] reported a ratio of $\mathrm{Pi} / \mathrm{PCr}$ peaking one or two days after exercise, which is similar to the results found in our study (Fig. 6). Additionally, the $\mathrm{Pi} / \mathrm{PCr}$ ratio correlated significantly with the perception of muscle soreness $(\mathrm{P}<0.01$, Fig. 7B). After $48 \mathrm{~h}$, the perception of muscle soreness achieved its maximum value [as reported by others, e. g., 40] and differed significantly from the CONTROL group $(\mathrm{P}<0.05$, Fig. 6$)$. This correlation makes perceived soreness rating an additional possible candidate for the judgement of the severity of the muscle fibers injury after eccentric exercise.

Often, CK [e.g., 41, 42] and $\mathrm{Mb}$ [e.g., 42] are used to

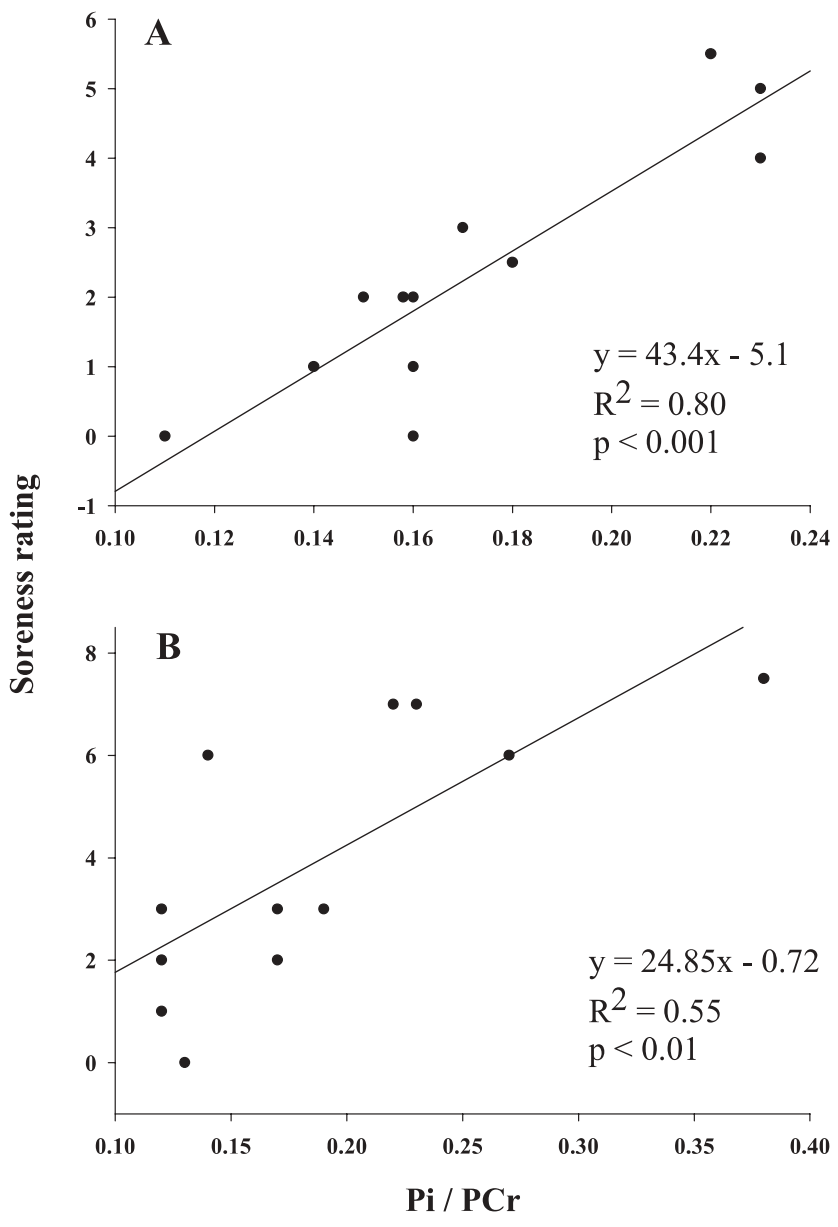

Fig. 7 Correlation between perceived muscle soreness and $\mathrm{Pi} / \mathrm{PCr}$ ratio in the DOMS group $2 \mathrm{~h}(\mathbf{A})$ and $48 \mathrm{~h}(\mathbf{B})$ after eccentric exercise

detect injured muscle fibers after eccentric exercise and to judge the severity of the damage. In our study, CK and $\mathrm{Mb}$ were both elevated in the course of recovery, but not significantly different in the two groups (Fig.5). From the shown results and other studies $[3,8,43,44]$ one can question the suitability of $\mathrm{CK}$ and $\mathrm{Mb}$ as indicators or predictors of muscle injury. Additionally, there is also a large inter-subject variability in the rise of CK [e.g., 45, 46]. However, $48 \mathrm{~h}$ after exercise, CK concentration was still elevated in the DOMS but not in the CONTROL group (Fig. 5). At the same time, the amount of glycogen in the DOMS group reached approximately resting concentration, which is a sign that CK does not negatively influence glycogen resynthesis (Fig. 3).

As a critique of the MRS method, one might argue that after eccentric exercise, swelling and storage of water in the contracted muscle can occur and could lead to a diminished glycogen signal in the ${ }^{13} \mathrm{C}$-spectra. However, substantial swelling and edema occur only $24 \mathrm{~h}$ after eccentric exercise [23,30,47,48]. The extent of swelling and edema after eccentric exercise was about 3 
to $9 \%$ [49]. This low fluid expansion is within the accuracy of MRS measurements [50] and would therefore hardly disturb such measurements.

\section{Conclusion}

Despite a high carbohydrate supply during recovery (>10 g CHO/kg BM/24h), the delay of muscle glycogen resynthesis after eccentric exercise could not be prevented. An important new finding was a further reduction of the glycogen concentration during the initial $2 \mathrm{~h}$ of recovery after eccentric exercise instead of a high resynthesis rate. Even $24 \mathrm{~h}$ after eccentric exercise, muscle glycogen concentration in the DOMS group was still
$35 \%$ below the resting concentration. The initial, further glycogen reduction and the delayed glycogen resynthesis were most likely an effect of muscle cell damage as indicated by increased $\mathrm{Pi}$ concentration and $\mathrm{Pi} / \mathrm{PCr}$ ratio. In consideration of this fact, it is probably impossible to eliminate the negative effect of muscle injury on the glycogen resynthesis after eccentric exercise even with a large supply of $\mathrm{CHO}$ during recovery.

Acknowledgments The authors thank Mirtha Arnold and Toni Moses for the analyses of the blood parameters and Wander (Neuenegg, Switzerland) as provider of the isotonic drink ISOSTAR LONG ENERGY. We would also like to thank Fred Brouns for the interesting exchanges of ideas about DOMS, Wim Saris for the revision of the manuscript, Markus Lamprecht for the help with the statistical analyses and Stephanie Frey for the corrections in English.

\section{References}

1. Lindstedt SL, LaStayo PC, Reich TE (2001) When active muscles lengthen: properties and consequences of eccentric contractions. News Physiol Sci 16: 256-261

2. Clarkson PM (1997) Eccentric exercise and muscle damage. Int J Sports Med 18:S314-S317

3. Komi PV,Viitasalo JT (1977) Changes in motor unit activity and metabolism in human skeletal muscle during and after repeated eccentric and concentric contractions. Acta Physiol Scand 100: 246-254

4. Asp S, Daugaard JR, Richter EA (1995) Eccentric exercise decreases glucose transporter Glut4 protein in human skeletal muscle. J Physiol (Lond) 482: 705-712

5. Costill DL, Pascoe DD, Fink WJ, Robergs RA, Barr SI, Pearson D (1990) Impaired muscle glycogen resynthesis after eccentric exercise. J Appl Physiol 69:46-50

6. Doyle JA, Sherman WM, Strauss RL (1993) Effects of eccentric and concentric exercise on muscle glycogen replenishment. J Appl Physiol 74: 1848-1855

7. Pascoe DD, Gladden LB (1996) Muscle glycogen resynthesis after short term, high intensity exercise and resistance exercise. Sports Med 21:98-118

8. Pascoe DD, Costill DL, Robergs RA, Davis JA, Fink WJ, Pearson DR (1990) Effects of exercise mode on muscle glycogen restorage during repeated days of exercise. Med Sci Sports Exerc 22:593-598

9. Widrick JJ, Costill DL, McConell GK, Anderson DE, Pearson DR, Zachwieja JJ (1992) Time course of glycogen accumulation after eccentric exercise. J Appl Physiol 72:1999-2004
10. Burke LM (1997) Nutrition for post-exercise recovery. Aust J Sci Med Sport 29: 3-10

11. Kirwan JP, Costill DL, Mitchell JB, Houmard JA, Flynn MG, Fink WJ, Beltz JD (1988) Carbohydrate balance in competitive runners during successive days of intense training. J Appl Physiol 65:2601-2606

12. Robergs RA (1991) Nutrition and exercise determinants of postexercise glycogen synthesis. Int J Sport Nutr 1: 307-337

13. Saris WH, van Erp-Baart MA, Brouns F, Westerterp KR, ten Hoor F (1989) Study on food intake and energy expenditure during extreme sustained exercise: the Tour de France. Int J Sports Med 10: S26-S31

14. Simonsen JC, Sherman WM, Lamb DR, Dernbach AR, Doyle JA, Strauss R (1991) Dietary carbohydrate, muscle glycogen, and power output during rowing training. J Appl Physiol 70: 1500-1505

15. Constantin-Teodosiu D, Casey A, Short AH, Hultman E, Greenhaff PL (1996) The effect of repeated muscle biopsy sampling on ATP and glycogen resynthesis following exercise in man. Eur J Appl Physiol 73:186-190

16. Costill DL, Pearson DR, Fink WJ (1988) Impaired muscle glycogen storage after muscle biopsy. J Appl Physiol 64: 2245-2248

17. Staron RS, Hikida RS, Murray TF, Nelson MM, Johnson P, Hagerman F (1992) Assessment of skeletal muscle damage in successive biopsies from strengthtrained and untrained men and women. Eur J Appl Physiol 65:258-264

18. Armstrong RB (1986) Muscle damage and endurance events. Sports Med 3: 370-381
19. Ryschon TW, Fowler MD, Wysong RE, Anthony A, Balaban RS (1997) Efficiency of human skeletal muscle in vivo: comparison of isometric, concentric, and eccentric muscle action. J Appl Physiol 83:867-874

20. McCully KK, Argov Z, Boden BP, Brown RL, Bank WJ, Chance B (1988) Detection of muscle injury in humans with 31-P magnetic resonance spectroscopy. Muscle Nerve 11:212-216

21. McCully KK, Kent JA, Chance B (1988) Application of 31P magnetic resonance spectroscopy to the study of athletic performance. Sports Med 5:312-321

22. Rodenburg JB, Degroot $\mathrm{MCH}$, Vanechteld CJA, Jongsma HJ, Bar PR (1995) Phosphate metabolism of prior eccentrically loaded vastus medialis muscle during exercise in humans. Acta Physiol Scand 153:97-108

23. Rodenburg JB, Deboer RW, Schiereck P, Vanechteld CJA, Bar PR (1994) Changes in phosphorus compounds and water content in skeletal muscle due to eccentric exercise. Eur J Appl Physiol 68: 205-213

24. Conconi F, Ferrari M, Ziglio PG, Droghetti P, Codeca L (1982) Determination of the anaerobic threshold by a noninvasive field test in runners. J Appl Physiol 52:869-873

25. Spencer RP (1977) CRC Handbook Series. In: Clinical Laboratory Science, Section A: Nuclear Medicine Volume I, Cleveland, CRC Press, p 165

26. Price TB, Laurent D, Petersen KF, Rothman DL, Shulman GI (2000) Glycogen loading alters muscle glycogen resynthesis after exercise. J Appl Physiol 88: 698-704 
27. Lund $H$, Vestergaard-Poulsen $P$, Kanstrup IL, Sejrsen P (1998) The effect of passive stretching on delayed onset muscle soreness, and other detrimental effects following eccentric exercise. Scand J Med Sci Sports 8:216-221

28. O’Reilly KP, Warhol MJ, Fielding RA, Frontera WR, Meredith CN, Evans WJ (1987) Eccentric exercise-induced muscle damage impairs muscle glycogen repletion. J Appl Physiol 63:252-256

29. Chasiotis D, Sahlin K, Hultman E (1982) Regulation of glycogenolysis in human muscle at rest and during exercise. J Appl Physiol 53:708-715

30. Entman ML, Keslensky SS, Chu A, Van Winkle WB (1980) The sarcoplasmic reticulum-glycogenolytic complex in mammalian fast twitch skeletal muscle. Proposed in vitro counterpart of the contraction-activated glycogenolytic pool. J Biol Chem 255:6245-6252

31. Hultman E, Greenhaff PL (1991) Skeletal muscle energy metabolism and fatigue during intense exercise in man. Sci Prog 75:361-370

32. Green HJ (1997) Mechanisms of muscle fatigue in intense exercise. J Sports Sci 15:247-256

33. Aldridge R, Cady EB, Jones DA, Obletter G (1986) Muscle pain after exercise is linked with an inorganic phosphate increase as shown by 31P NMR. Biosci Rep 6:663-667

34. Asp S, Rohde T, Richter EA (1997) Impaired muscle glycogen resynthesis after a marathon is not caused by decreased muscle GLUT-4 content. J Appl Physiol 83:1482-1485
35. Asp S, Daugaard JR, Kristiansen S, Kiens B, Richter EA (1996) Eccentric exercise decreases maximal insulin action in humans - muscle and systemic effects. J Physiol (Lond) 494:891-898

36. Ide K, Higaki Y, Nishizumi M, Kiyonaga A, Shindo M, Tanaka H (1996) Impaired non-insulin mediated glucose uptake after downhill running in rats. Life Sci 59:1601-1605

37. Kapur S, Bedard S, Marcotte B, Cote CH, Marette A (1997) Expression of nitric oxide synthase in skeletal muscle: a novel role for nitric oxide as a modulator of insulin action. Diabetes 46: 1691-1700

38. Schmidt HH, Walter U (1994) NO at work. Cell 78:919-925

39. Reid MB (1998) Role of nitric oxide in skeletal muscle: synthesis, distribution and functional importance. Acta Physiol Scand 162:401-409

40. Friden J, Sfakianos PN, Hargens AR, Akeson WH (1988) Residual muscular swelling after repetitive eccentric contractions. J Orthop Res 6:493-498

41. Pedersen BK, Ostrowski K, Rohde T, Bruunsgaard H (1998) The cytokine response to strenuous exercise. Can J Physiol Pharmacol 76:505-511

42. Sorichter S, Mair J, Koller A, Pelsers MM, Puschendorf B, Glatz JF (1998) Early assessment of exercise induced skeletal muscle injury using plasma fatty acid binding protein. Br J Sports Med 32:121-124
43. Kuipers H (1994) Exercise-induced muscle damage. Int J Sports Med 15: 132-135

44. Manfredi TG, Fielding RA, O’Reilly KP, Meredith CN, Lee HY, Evans WJ (1991) Plasma creatine kinase activity and exercise-induced muscle damage in older men. Med Sci Sports Exerc 23: 1028-1034

45. Clarkson PM, Ebbeling C (1988) Investigation of serum creatine kinase variability after muscle-damaging exercise. Clin Sci 75:257-261

46. Newham DJ, Jones DA, Edwards RH (1983) Large delayed plasma creatine kinase changes after stepping exercise. Muscle Nerve 6:380-385

47. Cleak MJ, Eston RG (1992) Muscle soreness, swelling, stiffness and strength loss after intense eccentric exercise. Br J Sports Med 26:267-272

48. Crenshaw AG, Thornell LE, Friden J (1994) Intramuscular pressure, torque and swelling for the exercise-induced sore vastus lateralis muscle. Acta Physiol Scand 152:265-277

49. Howell JN, Chleboun G, Conatser R (1993) Muscle stiffness, strength loss, swelling and soreness following exercise-induced injury in humans. J Physiol (Lond) 464:183-196

50. Buchli R, Boesiger P (1993) Comparison of methods for the determination of absolute metabolite concentrations in human muscles by 31P MRS. Magn Reson Med 30:552-558 